\section{Gender disparities in health and healthcare: results from the Portuguese National Health Interview Survey}

\author{
Disparidades de gênero na saúde e nos cuidados \\ de saúde: resultados para Portugal com base no \\ Inquérito Nacional de Saúde
}

\author{
${ }^{1}$ Escola Nacional de Saúde \\ Pública, Universidade Nova \\ de Lisboa, Lisboa, Portugal. \\ 2 Instituto Superior de \\ Ciências Sociais e Politicas, \\ Universidade Técnica de \\ Lisboa, Lisboa, Portugal. \\ Correspondence \\ J. Perelman \\ Escola Nacional de Saúde \\ Pública, Universidade Nova \\ de Lisboa. \\ Avenida Padre Cruz, Lisboa \\ 1600-560, Portugal. \\ jperelman@ensp.unl.pt
}

\begin{abstract}
Although women experience poorer health conditions during their lives, they live longer than men. The main explanations for this paradox suggest that women's excess of ill-health is limited to minor illnesses and their different attitudes toward health. The authors test these assumptions by investigating disparities between men and women in health and healthcare in Portugal. Data are used from the Portuguese National Health Interview Survey 2005/2006 ( $N=33,662)$. Multivariate regressions showed that women were more likely to report worse self-rated health, more days with disability, higher prevalence of hypertension, chronic pain, cancer, anxiety and depression, and more medical consultations. Heart disease was significantly more prevalent among men, possibly explaining part of the paradox. Women's more frequent use of medical consultations may reflect their heightened awareness of health problems, which may protect them against early death. Gender differences in socioeconomic status explain part of the differences in health, but fail to provide a complete understanding.
\end{abstract}

Gender Identity; Health Status Disparities; Healthcare Disparities; Socioeconomic Factors
Julian Perelman 1

Ana Fernandes 2

Céu Mateus ${ }^{1}$

\section{Introduction}

Recent reviews and studies on gender and health consistently point to a well-known and still unexplained paradox: although women experience poorer health conditions during their lives, on average they live longer than men 1,2,3,4. The main explanation suggests that women's excess of illhealth is limited to minor physical morbidity 5 , while men's illnesses are less frequent but more serious, explaining the higher male mortality rate at all ages 2,6,7. However, some authors report that women are also more likely to be affected by chronic conditions 3,8 and severe disability 9,10 , so the evidence remains ambiguous and the question unsolved.

Different attitudes toward health are an alternative explanation for the paradox. If women were more aware of their health status, leading to greater use of health care services, they would also be better protected against severe diseases that influence the probability of death 2 . Several studies have shown that women use primary care consultations more frequently 6,11,12, while men have higher hospitalization rate and longer average length of hospital stay, possibly reflecting a delay in their use of healthcare services 6 . These results may also confirm that men experience more severe health conditions.

The current article provides new evidence on gender disparities in health, based on data from Portugal on a wide range of severe and less 
severe health conditions. We test the hypothesis that women's poorer health is limited to milder conditions. We also investigate gender differences in healthcare use, allowing us to disentangle the possible role of different health-related attitudes on basis of gender. Finally, we investigate the causes of gender differences in health. To do so, we analyze the role of socioeconomic factors in the intermediate relationship between gender and health. Indeed, it is often argued that women's higher morbidity is related to their lower socioeconomic status, justifying the use of the gender concept. Among others, Annandale 13 (p. 148) posits that "if men and women were in the same role positions, there would be little or no difference in their health status". Still, other authors indicate that in each social category, women report higher rates of ill health than men 14 . Our study also contributes to this ongoing debate.

\section{Methods}

\section{The Portuguese National Health} Interview Survey

The data are from the Fourth National Health Interview Survey (INS), which was conducted in 2005 and 2006 in all regions of Continental Portugal. A sample of 19,581 private households was selected using a multi-stage random probability design, resulting in a nationally-representative sample of the non-institutionalized population in Portugal. The information was gathered by trained interviewers during face-to-face interviews with a household representative, including questions about health, lifestyle, healthcare use, and social and demographic conditions. The subjective health question was always answered by the individual her/himself. Quality control was conducted by re-administration of the same questionnaire to $10 \%$ of the initial sample (for more information on the INS, see the reference of the Instituto Nacional de Saúde Ricardo Jorge 15). Our analysis focuses on persons aged 18 or older, representing 33,662 individuals $(47.6 \%$ men and $52.4 \%$ women).

\section{Health status}

We used three types of indicators 16: subjective health (self-rated health and sick/unwell), functional health (restricted-activity days and bed days), and medical health (limiting chronic condition and chronic diseases).

Self-rated or subjective health relates to the individual's personal sense of well-being. It was measured with two questions: "Overall, how do you rate your state of health?" (on a 5-point scale from "very bad" to "very good") and "Have you felt sick or unwell in the last two weeks?" ("yes" or "no"). Self-rated health is a widely used health indicator that has been shown to be associated with early mortality 17 .

Functional health was measured by the prevalence of self-reported short-term limitations during the previous two weeks, using the number of days of restricted activities and the number of bed days (note that this indicator does not necessarily refer to inpatient days, but to days of complete immobilization, regardless of the setting). These variables measure whether the persons had to restrict their usual activities due to illness or injury.

Medical health was measured by chronic conditions. We measured the prevalence of the eight chronic diseases surveyed in the INS, which all represent a reduction in quality of life (asthma, diabetes, hypertension, chronic pain, rheumatic disease and osteoporosis, cancer, anxiety and depression, and cardiac disease). These indicators have been widely used to measure health inequity in Portugal 18.

\section{Healthcare use}

The first indicator was the total number of physician consultations. The second indicator distinguished between consultations with general practitioners and specialists. Since the INS only specifies the type of the most recent consultation, we defined the probability of having consulted with a general practitioner or specialist based on the immediately preceding consultation.

\section{Socioeconomic status}

Six indicators were used. First, education was measured using both "individual" (own level of schooling) and "dominant" (highest educational level in the household) approaches. Individual educational attainment is considered to be a good predictor of women's health 19. It is stable over the course of life and receives little or no influence from health status, thus limiting the risk of reverse causation. We measured education as credentials rather than years of schooling because they provide a better measure of market potential 20 . The household educational attainment was obtained by assigning to each person the attainment of his/her parent who had achieved the highest educational level. This procedure is useful for many people in the 18-25 age range who have not completed their education. It is also a way to differentiate between elderly women, who mostly have low education. Edu- 
cational groups were constructed based on the International Standard Classification of Education (ISCED-97) 21.

Second, employment status indicated whether the person was currently part of the labor force. Among those not in the active labor force, we distinguished the unemployed, housewives, retired persons, and those out of the labor force for other reasons (mainly disabled and students). Employment status is one of the most important variables associated with health in both men and women 19.

Third, we used an indicator for income. Respondents were asked to tick one of ten income categories that was the best proxy for their household's disposable income in the previous month. To calculate individual income, we applied the rule used in the most recent studies on incomerelated health inequity, using the "OECD-modified" equivalence scale 22 . Based on this scale, we assigned a weight of 1 to the first adult, 0.5 to the second adult and each subsequent person aged 14 and over, and 0.3 to anyone under 14 .

Fourth, we included a variable for health insurance status. The Portuguese National Health Service (SNS) provides universal coverage. Private insurers provide supplementary coverage to around $10 \%$ of the population and are financed through individual risk-adjusted contributions. Access to private insurance is an important indicator of socioeconomic status, due to its strong association with economic resources. Additionally, private and public occupational or professional insurance schemes provide coverage for around $16 \%$ of the population, allowing access to some private providers at low co-payment rates; this coverage also correlated with social status (for more details on the Portuguese health care system, see Barros et al. 23).

Fifth, marital status was used because having a partner acts as a source of social support that can buffer against adverse health effects 10 . Finally, we included an indicator for occupation, whose influence on health has been widely demonstrated and tends to vary with gender 24 . Occupational groups were based on the International Standard Classification of Occupations (ISCO-2008; http://www.ilo.org/public/english/ bureau/stat/isco/index.htm, accessed on 05/ Sep/2012), although we were limited to four categories instead of five due to the classes used in the National Health Interview Survey.

\section{Analysis}

A descriptive analysis was performed first to compare health status, healthcare use, and socioeconomic status between men and women.
Student t confidence intervals were calculated for quantitative measures and chi-square was used to test for statistically significant differences in categorical variables.

Three analyses were performed using different modeling techniques.

We measured the association between gender and health status, controlling for age. Multivariate logistic regression was performed for binary dependent variables: self-rated health and each of the eight chronic diseases. The number of disability days and bed days were both modeled using count data regressions, given the nonnegative integer-value nature of the data. A negative binomial model was used to account for data over-dispersion related to the relevant proportion of zeros.

We measured the association between gender and medical visits, general practitioner consultations, and specialist consultations. Given the non-negative integer-value nature of the data, we used count data regressions to model the number of visits, controlling for age and all health condition variables, added one by one. For disability and bed days, a negative binomial model was found to be more accurate. We kept only those health condition variables that significantly affected healthcare use. We modeled the probabilities of a general practitioner consultation and a specialist consultation using multivariate logistic regression, using the same procedure as for adjustment variables.

We estimated the effect of the inclusion of socioeconomic status indicators (as independent variables) on the association between gender, health, and healthcare use. One separate regression was performed for each socioeconomic status indicator included as risk-adjustor; then, a regression was performed including all socioeconomic status indicators. We compared the coefficients obtained for gender before and after adjusting for socioeconomic status.

\section{Results}

\section{Descriptive analysis}

Table 1 shows health status and health care use. Men were more likely to rate their health as "good" and "very good" and less likely to report illness. The number of days with restricted activity was significantly higher among women, but differences for bed days were not significant at $1 \%$. Prevalence of chronic diseases was significantly higher among women for all conditions except cardiac disease (more prevalent among men). Women also used more medical visits and 
Table 1

Health status and healthcare use by gender $(\mathrm{N}=33,662)$, Portuguese National Health Interview Survey.

\begin{tabular}{|c|c|c|c|}
\hline Variable & Women $(n=17,640)$ & $\operatorname{Men}(n=16,022)$ & p-value \\
\hline Total & $52.4 \%$ & $47.6 \%$ & \\
\hline \multicolumn{4}{|l|}{ Age (years) } \\
\hline $18-34$ & $22.2 \%$ & $26.8 \%$ & $<0.001$ \\
\hline $35-44$ & $16.9 \%$ & $17.1 \%$ & \\
\hline $45-64$ & $32.9 \%$ & $32.6 \%$ & \\
\hline $65-74$ & $16.1 \%$ & $13.8 \%$ & \\
\hline$>75$ & $11.9 \%$ & $9.6 \%$ & \\
\hline \multicolumn{4}{|l|}{ Health status } \\
\hline \multicolumn{4}{|l|}{ Subjective health * } \\
\hline Very bad & $5.5 \%$ & $3.3 \%$ & $<0.001$ \\
\hline Bad & $17.8 \%$ & $12.3 \%$ & \\
\hline Fair & $42.3 \%$ & $37.8 \%$ & \\
\hline Good & $29.2 \%$ & $37.8 \%$ & \\
\hline Very good & $5.3 \%$ & $8.8 \%$ & \\
\hline Illness & $19.7 \%$ & $13.6 \%$ & $<0.001$ \\
\hline No illness & $80.3 \%$ & $86.4 \%$ & \\
\hline \multicolumn{4}{|l|}{ Functional health } \\
\hline Number of restricted activity days (mean) & 0.82 & 0.60 & $<0.001$ \\
\hline Number of bed days (mean) & 2.40 & 2.58 & 0.014 \\
\hline \multicolumn{4}{|l|}{ Medical conditions } \\
\hline Asthma & $5.8 \%$ & $4.7 \%$ & $<0.001$ \\
\hline Diabetes & $9.7 \%$ & $7.9 \%$ & $<0.001$ \\
\hline Hypertension & $30.7 \%$ & $21.6 \%$ & $<0.001$ \\
\hline Chronic pain & $20.7 \%$ & $13.5 \%$ & $<0.001$ \\
\hline Rheumatic disease, osteoporosis & $31.2 \%$ & $14.7 \%$ & $<0.001$ \\
\hline Cancer & $2.8 \%$ & $1.8 \%$ & $<0.001$ \\
\hline Anxiety, depression & $16.0 \%$ & $5.3 \%$ & $<0.001$ \\
\hline Cardiac disease & $3.1 \%$ & $4.7 \%$ & $<0.001$ \\
\hline \multicolumn{4}{|l|}{ Healthcare use } \\
\hline Number of visits (mean) & 1.29 & 0.92 & $<0.001$ \\
\hline General practitioner consultations & $60.4 \%$ & $39.6 \%$ & $<0.001$ \\
\hline Specialist consultations & $80.5 \%$ & $19.5 \%$ & $<0.001$ \\
\hline
\end{tabular}

* For subjective health variables, calculations were made on the 23,202 non-missing observations. There were 10,460 missing values, since individuals themselves had to answer this question.

were much more likely to have consulted with both general practitioners and specialists.

Table 2 shows socioeconomic characteristics. There were proportionally more women than men with no schooling. Differences were reduced by construction when we considered the highest educational attainment in the household. Men were more likely to be employed, but only small differences were observed in unemployment rates. Men had higher mean income and were more likely to have private insurance and occupy job positions.

\section{Multivariate analysis}

Table 3 shows the results from multivariate regressions on health status. Controlling for age but for none of factors related to socioeconomic status, women were more likely to have poorer health status according to all indicators except bed days (which showed no significant difference) and cardiac disease (more prevalent among men). Men and women showed large differences for the two self-rated health indicators, where women were twice as likely to report illness or "bad" or "very bad" health. There was also a strong association 
Socioeconomic characteristics by gender $(N=33,662)$.

\begin{tabular}{|c|c|c|c|}
\hline Variable & Women $(n=17,640)$ & $\operatorname{Men}(n=16,022)$ & $\mathrm{p}$-value \\
\hline Total & $52.4 \%$ & $47.6 \%$ & \\
\hline \multicolumn{4}{|l|}{ "Individual” schooling } \\
\hline None & $19.5 \%$ & $11.6 \%$ & $<0.001$ \\
\hline Primary & $35.0 \%$ & $37.5 \%$ & \\
\hline Junior high & $22.3 \%$ & $29.2 \%$ & \\
\hline Secondary \& post-secondary & $11.7 \%$ & $12.7 \%$ & \\
\hline University & $11.4 \%$ & $9.0 \%$ & \\
\hline \multicolumn{4}{|l|}{ "Dominant" schooling } \\
\hline None & $9.4 \%$ & $5.7 \%$ & $<0.001$ \\
\hline Primary & $24.7 \%$ & $23.8 \%$ & \\
\hline Junior high & $26.9 \%$ & $30.7 \%$ & \\
\hline Secondary \& post-secondary & $19.7 \%$ & $20.8 \%$ & \\
\hline University & $19.3 \%$ & $18.9 \%$ & \\
\hline \multicolumn{4}{|l|}{ Employment status } \\
\hline Housewife & $20.1 \%$ & $0.1 \%$ & $<0.001$ \\
\hline Unemployed & $4.4 \%$ & $4.6 \%$ & \\
\hline Retired & $23.1 \%$ & $24.9 \%$ & \\
\hline Employed & $44.6 \%$ & $61.8 \%$ & \\
\hline Others out of labor force & $7.9 \%$ & $8.5 \%$ & \\
\hline Income (mean) & 601.84 & 628.27 & $<0.001$ \\
\hline \multicolumn{4}{|l|}{ Insurance } \\
\hline Private insurance & $6.8 \%$ & $8.4 \%$ & $<0.001$ \\
\hline Subsystems & $16.7 \%$ & $15.0 \%$ & \\
\hline National health service & $78.6 \%$ & $78.2 \%$ & \\
\hline \multicolumn{4}{|l|}{ Marital status * } \\
\hline Married or living with partner & $64.0 \%$ & $70.4 \%$ & $<0.001$ \\
\hline Divorced, separated & $4.3 \%$ & $2.4 \%$ & \\
\hline Widowed & $14.9 \%$ & $3.4 \%$ & \\
\hline Single & $16.9 \%$ & $23.8 \%$ & \\
\hline \multicolumn{4}{|l|}{ Occupation } \\
\hline Managerial, professional & $11.5 \%$ & $12.7 \%$ & $<0.001$ \\
\hline Technical, sales, administrative & $35.3 \%$ & $23.5 \%$ & \\
\hline Manual & $28.3 \%$ & $52.6 \%$ & \\
\hline None & $22.9 \%$ & $11.1 \%$ & \\
\hline
\end{tabular}

* Categories divorced/separated and widowed did not include people with this status who were living with a partner.

with self-reported anxiety and depression $(\mathrm{OR}=$ 3.375), hypertension $(\mathrm{OR}=1.558)$, chronic pain $(\mathrm{OR}=1.593)$, and cancer $(\mathrm{OR}=1.418)$.

The inclusion of socioeconomic variables generally reduced the odds ratios. In particular, the association with gender lost significance for diabetes, while the number of bed days became significantly higher among men. Nonetheless, for other health measures, estimates did not vary greatly in magnitude or statistical significance. Socioeconomic adjustment increased the gender gap for chronic pain and rheumatic disease, that is, these diseases were more likely to affect women from higher socioeconomic brackets. Finally, individual education contributed the most to reducing gender inequality in subjective health; however, as for chronic conditions, although no clear pattern emerged, employment status and occupation contributed more to explaining gender inequalities.

Table 4 shows the results for the association between gender and healthcare use. Women showed a significantly higher use of all medical consultations and were significantly more likely 
Table 3

Association between gender and health status according to age-adjusted odds ratios.

\begin{tabular}{|c|c|c|c|c|}
\hline \multirow[t]{2}{*}{ SES adjustor } & \multicolumn{4}{|c|}{ Health status indicator } \\
\hline & SAH1 & $\mathrm{SAH} 2$ & Disability days * & Bed days * \\
\hline \multirow[t]{2}{*}{ No SES } & 2.111 & 1.507 & 1.267 & 0.901 \\
\hline & $(1.968-2.263)$ & $(1.417-1.604)$ & $(1.164-1.379)$ & $(0.797-1.018)$ \\
\hline \multirow[t]{2}{*}{ "Individual" schooling } & 1.991 & 1.496 & 1.275 & 0.908 \\
\hline & $(1.854-2.137)$ & $(1.405-1.593)$ & $(1.171-1.389)$ & $(0.804-1.026)$ \\
\hline \multirow[t]{3}{*}{ "Dominant" schooling } & 2.074 & 1.504 & 1.274 & 0.912 \\
\hline & $(1.932-2.226)$ & $(1.413-1.601)$ & & \\
\hline & & & $(1.171-1.387)$ & $(0.807-1.030)$ \\
\hline \multirow[t]{2}{*}{ Employment status } & 2.031 & 1.508 & 1.334 & 0.881 \\
\hline & $(1.884-2.189)$ & $(1.412-1.610)$ & $(1.221-1.458)$ & (0.777-0.999) \\
\hline \multirow[t]{2}{*}{ Income } & 2.056 & 1.506 & 1.265 & 0.903 \\
\hline & $(1.915-2.207)$ & $(1.414-1.603)$ & $(1.162-1.378)$ & $(0.799-1.022)$ \\
\hline \multirow[t]{2}{*}{ Insurance } & 2.080 & 1.508 & 1.274 & 0.899 \\
\hline & $(1.939-2.232)$ & $(1.417-1.604)$ & $(1.171-1.387)$ & $(0.795-1.016)$ \\
\hline \multirow[t]{2}{*}{ Marital status } & 2.096 & 1.495 & 1.287 & 0.907 \\
\hline & $(1.950-2.254)$ & $(1.403-1.593)$ & $(1.179-1.404)$ & (0.799-1.030) \\
\hline \multirow[t]{2}{*}{ Occupation } & 2.194 & 1.557 & 1.403 & 0.856 \\
\hline & $(2.031-2.371)$ & $(1.456-1.666)$ & $(1.280-1.538)$ & $(0.749-0.978)$ \\
\hline \multirow[t]{3}{*}{ All SES } & 2.077 & 1.514 & 1.453 & 0.868 \\
\hline & $(1.912-2.256)$ & $(1.412-1.625)$ & $(1.319-1.601)$ & $(0.756-0.997)$ \\
\hline & Asthma & Diabetes & Hypertension & Chronic pain \\
\hline \multirow[t]{2}{*}{ No SES } & 1.209 & 1.144 & 1.558 & 1.593 \\
\hline & $(1.097-1.332)$ & $(1.058-1.238)$ & $(1.475-1.646)$ & $(1.501-1.690)$ \\
\hline \multirow[t]{2}{*}{ "Individual" schooling } & 1.173 & 1.128 & 1.560 & 1.571 \\
\hline & $(1.064-1.294)$ & $(1.041-1.221)$ & $(1.476-1.648)$ & $(1.480-1.669)$ \\
\hline \multirow[t]{2}{*}{ "Dominant" schooling } & 1.202 & 1.147 & 1.561 & 1.581 \\
\hline & $(1.091-1.325)$ & $(1.060-1.241)$ & $(1.478-1.649)$ & (1.489-1.678) \\
\hline \multirow[t]{2}{*}{ Employment status } & 1.193 & 1.087 & 1.533 & 1.608 \\
\hline & $(1.077-1.321)$ & (0.999-1.183) & $(1.446-1.625)$ & $(1.510-1.713)$ \\
\hline \multirow[t]{2}{*}{ Income } & 1.199 & 1.137 & 1.546 & 1.584 \\
\hline & $(1.087-1.322)$ & $(1.050-1.231)$ & $(1.463-1.633)$ & $(1.491-1.683)$ \\
\hline \multirow[t]{2}{*}{ Insurance } & 1.210 & 1.134 & 1.557 & 1.594 \\
\hline & (1.098-1.333) & $(1.048-1.227)$ & $(1.474-1.644)$ & $(1.502-1.692)$ \\
\hline \multirow[t]{2}{*}{ Marital status } & 1.170 & 1.121 & 1.540 & 1.591 \\
\hline & (1.059-1.292) & $(1.033-1.216)$ & $(1.456-1.630)$ & $(1.496-1.691)$ \\
\hline \multirow[t]{2}{*}{ Occupation } & 1.191 & 1.094 & 1.562 & 1.667 \\
\hline & $(1.072-1.323)$ & $(1.003-1.194)$ & $(1.471-1.659)$ & $(1.562-1.780)$ \\
\hline \multirow[t]{2}{*}{ All SES } & 1.128 & 1.049 & 1.516 & 1.645 \\
\hline & $(1.011-1.258)$ & $(0.958-1.150)$ & $(1.423-1.614)$ & $(1.537-1.761)$ \\
\hline
\end{tabular}

(continues) 
Table 3 (continued)

\begin{tabular}{|c|c|c|c|c|}
\hline & $\begin{array}{c}\text { Rheumatic disease, } \\
\text { osteoporosis }\end{array}$ & Cancer & Anxiety, depression & Cardiac disease \\
\hline No SES & $\begin{array}{c}2.767 \\
(2.608-2.936)\end{array}$ & $\begin{array}{c}1.418 \\
(1.224-1.643)\end{array}$ & $\begin{array}{c}3.375 \\
(3.113-3.658)\end{array}$ & $\begin{array}{c}0.540 \\
(0.481-0.607)\end{array}$ \\
\hline "Individual" schooling & $\begin{array}{c}2.745 \\
(2.585-2.914)\end{array}$ & $\begin{array}{c}1.476 \\
(1.272-1.712)\end{array}$ & $\begin{array}{c}3.515 \\
(3.241-3.812)\end{array}$ & $\begin{array}{c}0.537 \\
(0.477-0.603)\end{array}$ \\
\hline "Dominant" schooling & $\begin{array}{c}2.763 \\
(2.604-2.932)\end{array}$ & $\begin{array}{c}1.448 \\
(1.249-1.678)\end{array}$ & $\begin{array}{c}3.427 \\
(3.161-3.715)\end{array}$ & $\begin{array}{c}0.546 \\
(0.486-0.614)\end{array}$ \\
\hline Employment status & $\begin{array}{c}2.764 \\
(2.596-2.994)\end{array}$ & $\begin{array}{c}1.361 \\
(1.164-1.591)\end{array}$ & $\begin{array}{c}3.329 \\
(3.062-3.620)\end{array}$ & $\begin{array}{c}0.549 \\
(0.485-0.622)\end{array}$ \\
\hline Income & $\begin{array}{c}2.719 \\
(2.561-2.887)\end{array}$ & $\begin{array}{c}1.404 \\
(1.210-1.628)\end{array}$ & $\begin{array}{c}3.382 \\
(3.117-3.669)\end{array}$ & $\begin{array}{c}0.544 \\
(0.484-0.611)\end{array}$ \\
\hline Insurance & $\begin{array}{c}2.759 \\
(2.600-2.928)\end{array}$ & $\begin{array}{c}1.418 \\
(1.223-1.643)\end{array}$ & $\begin{array}{c}3.375 \\
(3.114-3.659)\end{array}$ & $\begin{array}{c}0.537 \\
(0.478-0.603)\end{array}$ \\
\hline Marital status & $\begin{array}{c}2.778 \\
(2.613-2.953)\end{array}$ & $\begin{array}{c}1.441 \\
(1.238-1.678)\end{array}$ & $\begin{array}{c}3.227 \\
(3.019-3.556)\end{array}$ & $\begin{array}{c}0.535 \\
(0.473-0.604)\end{array}$ \\
\hline Occupation & $\begin{array}{c}2.848 \\
(2.669-3.040)\end{array}$ & $\begin{array}{c}1.370 \\
(1.167-1.608)\end{array}$ & $\begin{array}{c}3.235 \\
(2.968-3.526)\end{array}$ & $\begin{array}{c}0.566 \\
(0.498-0.643)\end{array}$ \\
\hline All SES & $\begin{array}{c}2.813 \\
(2.628-3.011)\end{array}$ & $\begin{array}{c}1.366 \\
(1.157-1.613)\end{array}$ & $\begin{array}{c}3.104 \\
(2.841-3.392)\end{array}$ & $\begin{array}{c}0.550 \\
(0.480-0.630)\end{array}$ \\
\hline
\end{tabular}

SAH: self-rated health; SES: socioeconomic status.

* Values correspond to age-adjusted incident rate ratios.

Table 4

Association between gender and healthcare use according to age- and health condition-adjusted incident rate ratios.

\begin{tabular}{|c|c|c|c|}
\hline \multirow[t]{2}{*}{ SES adjustor } & \multicolumn{3}{|c|}{ Healthcare use indicator } \\
\hline & Number of visits & General practitioner visits * & Specialist visits * \\
\hline \multirow[t]{2}{*}{ No SES } & 1.117 & 1.161 & 1.133 \\
\hline & $(1.069-1.168)$ & $(1.090-1.237)$ & $(1.048-1.225)$ \\
\hline \multirow[t]{2}{*}{ "Individual" schooling } & 1.126 & 1.157 & 1.159 \\
\hline & $(1.077-1.177)$ & $(1.086-1.233)$ & $(1.070-1.256)$ \\
\hline \multirow[t]{2}{*}{ "Dominant" schooling } & 1.120 & 1.152 & 1.153 \\
\hline & $(1.071-1.171)$ & $(1.081-1.227)$ & $(1.065-1.248)$ \\
\hline \multirow[t]{2}{*}{ Employment status } & 1.165 & 1.191 & 1.190 \\
\hline & $(1.113-1.221)$ & $(1.115-1.273)$ & $(1.097-1.291)$ \\
\hline \multirow[t]{2}{*}{ Income } & 1.119 & 1.157 & 1.143 \\
\hline & $(1.070-1.169)$ & $(1.085-1.232)$ & $(1.056-1.238)$ \\
\hline \multirow[t]{2}{*}{ Insurance } & 1.124 & 1.163 & 1.141 \\
\hline & $(1.075-1.175)$ & (1.092-1.239) & $(1.055-1.235)$ \\
\hline \multirow[t]{2}{*}{ Marital status } & 1.125 & 1.159 & 1.159 \\
\hline & $(1.076-1.177)$ & $(1.087-1.236)$ & $(1.071-1.255)$ \\
\hline \multirow[t]{2}{*}{ Occupation } & 1.151 & 1.210 & 1.094 \\
\hline & $(1.099-1.206)$ & $(1.130-1.295)$ & $(1.006-1.191)$ \\
\hline \multirow[t]{2}{*}{ All SES } & 1.162 & 1.203 & 1.144 \\
\hline & $(1.108-1.219)$ & $(1.121-1.292)$ & $(1.047-1.249)$ \\
\hline
\end{tabular}

SES: socioeconomic status.

*Values correspond to age- and health condition-adjusted odds ratios. 
to consult general practitioners and specialists, and inequalities between women and men increased when socioeconomic factors were included in the analysis. In other words, women's use of healthcare was underestimated due to their higher degree of social deprivation as compared to men. Employment status and occupation were the main factors in the increase in incident rate ratios and odds ratios for consultations with general practitioners. Regarding specialist consultations, employment and marital status contributed more substantially to increase odds ratios.

\section{Discussion}

This study focused on gender differences in health and healthcare in Portugal using data from the INS. Controlling for age and socioeconomic status, our research showed that women were more likely to report poorer subjective health, more days lost to disability, and higher prevalence of several chronic conditions, except cardiac disease (more prevalent among men) and diabetes (no significant differences). Men experienced significantly more bed days. Finally, women showed significantly greater use of healthcare services.

The difference between men and women in self-rated health was consistent with some studies in the literature $3,5,6$, while contradicting others $8,10,25$. Compared to earlier studies, gender disparity was high, even when adjusted for socioeconomic status.

Women suffered more from partially restricted activity (number of disability days), confirming earlier results 6 . By contrast, men were more affected by complete restrictions. Nevertheless, we cannot argue that women's illnesses were more frequent while being less severe 5,10,26. We observed a higher prevalence of milder chronic conditions among women, such as asthma and chronic pain, but also hypertension, cancer, anxiety, and depression. Note that diabetes was more prevalent among women, but this difference can be explained by women's disadvantaged social status. The only exception was for cardiac disease, significantly more prevalent among men. Women's health status was thus worse in some cases - undoubtedly self-rated health and milder chronic conditions - but was also higher among men for most severe conditions, rejecting the assumption of a "male disadvantage" associated with chronic diseases. The exception of cardiac disease, significantly more prevalent among men, was noticeable. In Portugal, ischemic heart disease is the second cause of death (following cerebrovascular disease) 27 . Hence, the higher prevalence of cardiac disease in men may partially explain men's lower life expectancy/better health paradox, as suggested by empirical evidence from the United States over a 14-year pe$\operatorname{riod} 2$.

Socioeconomic status reduced the magnitude of gender differences, which however remained large and significant. Individual education, occupation, and employment are the variables with the greatest influence on gender-based health patterns. Women are commonly found to be disadvantaged in access to economic resources and high social status 25 , which are strong determinants of good health. The persistence of gender differences after controlling for social determinants may have different interpretations The "social role" hypothesis postulates that the experience of a given social position (work load, stress, and self-esteem) differs between men and women, with different consequences for health 14. In Portugal, despite the high rate of women's full-time employment, gender inequality persists in the distribution of domestic tasks, women suffer from lower recognition at work (through lower pay and less access to leadership positions), and single mothers receive little formal support 28. According to the "differential vulnerability hypothesis", women and men react differently to structural factors, and women are more affected by social determinants, life events, chronic stressors, and psychological resources 3 . Interestingly, recent studies report that the health effects of childhood socioeconomic status are worse for women 29,30; that is, girls and boys are affected differently by adverse socioeconomic circumstances, for example, through childhood disadvantage contributing to gender discrimination later in life.

In this study, women's significantly higher use of healthcare services corroborated earlier results 6,9 . Women's higher health care use was observed even among individuals with similar morbidity, and socioeconomic differences between men and women were not the main cause of the observed discrepancies. Women's greater use of healthcare was also observed for specialist visits, thereby confirming that women's excess of ill health was not restricted to milder conditions. These findings may help explain why women die later, even if they are ill more frequently. Women may actually be more aware of their health needs and make greater use of preventive healthcare, with positive effects on early diagnosis and life expectancy.

This study's limitations are common in national health surveys, which rely on limited population samples, with data collected over a limited time period. Subjects were asked about 
their overall health status and a given number of chronic conditions, lacking more detailed information on diseases and treatments. Information was only requested on the most recent medical visits, assuming that the specialty involved in the most recent consultation was the same as in previous ones. Some socioeconomic factors can be criticized as excessively biased and unreliable; in particular, income is known to be affected by high non-response rates and bias due to differences between current and permanent amounts 20 , which led us to use a wider range of socioeconomic variables. Despite their weaknesses, national health interview surveys have been used in many countries and provided valuable results.

Our results clearly confirmed the excess of ill-health among Portuguese women for a large number of health conditions, including the most severe ones (except cardiac disease). Hence the paradox is still why men show shorter life expectancy despite their better health, even if cardiac disease represents a crucial factor. Longitudinal studies should help provide a better understanding of how and when health conditions differ between men and women and the relationship with premature death. In Portugal, as elsewhere, women use health services more, possibly reflecting their poorer health, but also perhaps their better knowledge and awareness of health problems, which may protect them against early death. Gender differences in socioeconomic status explain part of the differences in health, but fail to provide a complete understanding. Further research should include more specific socioeconomic and psychosocial determinants that could help elucidate the causal pathway between gender and health.

\section{Resumo}

Embora tenham pior saúde ao longo da vida, as mulheres vivem mais anos do que os homens. As principais explicações para este paradoxo são que as mulheres sofrem mais de doenças menores, e adotam atitudes diferentes em relação à saúde. Testamos essas hipóteses pela investigação de disparidades entre homens e mulheres na saúde e nos cuidados de saúde em Portugal. Os dados usados são do Inquérito Nacional de Saúde 2005/2006 ( $N$ = 33.662). Regressões multivariadas mostram que as mulheres declaram pior estado de saúde autoavaliado, maior número de dias de incapacidade, maior prevalência de hipertensão, dor crônica, cancro, ansiedade e depressão, e maior utilização de consultas. A doença cardíaca é significativamente mais prevalente nos homens, o que pode explicar em parte o paradoxo. A maior utilização de consultas nas mulheres pode refletir a sua maior consciência relacionada com a saúde, que talvez seja protetora contra a morte precoce. Diferenças de gênero no estatuto socioeconômico explicam parte das diferenças em saúde, mas não permitem uma compreensão completa das diferenças.

Identidade de Gênero; Disparidades nos Níveis de Saúde; Disparidades em Assistência à Saúde; Fatores Socioeconômicos

\section{Contributors}

J. Perelman participated in the study design, conducted the data analysis, and drafted the manuscript. A. Fernandes participated in the study design and revised the manuscript. C. Mateus participated in the study design, data collection, and interpretation of the results and performed a systematic revision of all versions of the draft.

\section{Acknowledgments}

The current study was part of a larger research project aimed at measuring gender disparities in health and healthcare including health status and waiting times for surgery and ambulatory care, and was financed by the Portuguese Ministry of Health, which we gratefully acknowledge. 


\section{References}

1. Read JG, Gorman BK. Gender and health inequality. Annu Rev Sociol 2010; 36:371-86.

2. Case A, Paxson CH. Sex differences in mortality and morbidity. Demography 2005; 42:189-214.

3. Denton M, Prus S, Walters V. Gender differences in health: a Canadian study of the psychosocial, structural and behavioural determinants of health. Soc Sci Med 2004; 58:2585-600.

4. Idler EL. Discussion: gender differences in selfrated health, in mortality, and in the relationship between the two. Gerontologist 2003; 43:372-5.

5. Macintyre S, Hunt K, Sweeting H. Gender differences in health: are things really as simple as they seem? Soc Sci Med 1996; 42:617-24.

6. Verbrugge LM. Sex differentials in health. Public Health Rep 1982; 97:417-37.

7. Verbrugge LM. Gender and health: an update on hypothesis and evidence. J Health Soc Behav 1985; 26:156-82.

8. McDonough P, Walters V. Gender and health: reassessing patterns and explanations. Soc Sci Med 2001; 52:547-59

9. Wingard DL. The sex differential in morbidity, mortality, and lifestyle. Annu Rev Public Health 1984; 5:433-58.

10. Arber S, Cooper H. Gender differences in health in later life: the new paradox? Soc Sci Med 1999; 48:61-76.

11. Cleary PD, Mechanic D, Greenley JR. Sex differences in medical care utilization: an empirical investigation. J Health Soc Behav 1982; 23:106-19.

12. Bertakis KD, Azari R, Helms LJ, Callahan EJ, Robbins JA. Gender differences in the utilization of health care services. J Fam Pract 2000; 49:147-52.

13. Annandale E. The sociology of health and medicine: a critical introduction. Cambridge: Polity Press; 1998.

14. Popay J, Bartley M, Owen C. Gender inequalities in health: social position, affective disorders and minor physical morbidity. Soc Sci Med 1993; 36: 21-32.

15. Instituto Nacional de Saúde Ricardo Jorge. Inquérito Nacional de Saúde 2005/2006. Lisboa: Instituto Nacional de Saúde Ricardo Jorge; 2008.

16. Blaxter M. A comparison of measures of inequality in morbidity. In: Fox J, editor. Health inequality in European countries. London: Aldershot Gower Publishing Co.; 1989. p. 199-230.

17. Idler EL, Benyamini Y. Self-rated health and mortality: a review of twenty-seven community studies. J Health Soc Behav 1997; 38:21-37.

18. Lopes S. Equity in the delivery of health care in Portugal: evidence from the 1998/99 national health interview survey [Masters Thesis]. York: University of York; 2004.
19. Arber S. Comparing inequalities in women's and men's health: Britain in the 1990s. Soc Sci Med 1997; 44:773-87.

20. Krieger N, Williams DR, Moss NE. Measuring social class in US public health research: concepts, methodologies and guidelines. Annu Rev Public Health 1997; 18:341-78.

21. United Nations Educational Scientific and Cultural Organization. ISCED 97 - International Standard Classification of Education. Montreal: United Nations Educational Scientific and Cultural Organization; 2006.

22. van Doorslaer E, Koolman X. Explaining the differences in income-related health inequalities across European countries. Health Econ 2004; 13:609-28.

23. Barros PP, Machado SR, Simões JA. Portugal. Health system review. Health Syst Transit 2011; 13:1-156

24. Aldabe B, Anderson R, Lyly-Yrjanainen M, ParentThirion A, Vermeylen G, Kelleher CC, et al. Contribution of material, occupational, and psychosocial factors in the explanation of social inequalities in health in 28 countries in Europe. J Epidemiol Community Health 2011; 65:1123-31.

25. Charles M. A world of difference: international trends in women's economic status. Annu Rev Sociol 2011; 37:355-71.

26. Lahelma E, Martikainen P, Rahkonen O, Silventoinen K. Gender differences in ill health in Finland: patterns, magnitude and change. Soc Sci Med 1999; 48:7-19.

27. Direcção-Geral da Saúde. Elementos estatísticos: informação geral - saúde/2008. Lisboa: DirecçãoGeral da Saúde; 2008.

28. Torres A. Women, gender, and work: the Portuguese case in the context of the European Union. Int J Sociol 2008; 38:36-56.

29. Strand BH, Murray ET, Guralnik J, Hardy R, Kuh D. Childhood social class and adult adiposity and blood-pressure trajectories 36-53 years: genderspecific results from a British birth cohort. J Epidemiol Community Health 2012; 66:512-8.

30. Maty SC, Lynch JW, Raghunathan TE, Kaplan GA. Childhood socioeconomic position, gender, adult body mass index, and incidence of type 2 diabetes mellitus over 34 years in the Alameda County Study. Am J Public Health 2008; 98:1486-94.

Submitted on 29/Mar/2012

Final version resubmitted on 09/Aug/2012

Approved on 17/Aug/2012 